\title{
Agricultural Production Behavior under Premium Subsidy: Incorporating Crop Price When Subsistence Constraint Holds
}

\author{
Tao Ye ${ }^{1,2, *}$, Muneta Yokomatsu ${ }^{2}$, and Norio Okada ${ }^{2}$ \\ ${ }^{1}$ State Key Laboratory of Earth Surface Processes and Resource Ecology, Beijing Normal University, Beijing 100875, China \\ ${ }^{2}$ Disaster Prevention Research Institute, Kyoto University, Uji 6110011, Japan
}

\begin{abstract}
Producers' acreage decisions in response to the availability of insurance and government subsidy has been a topic of considerable attention. This study revisits the issue of agriculture producers' production behavior under crop insurance and premium subsidy conditions. The discussion begins by differentiating between the assumptions of the classic insurance model and that model's application to crop insurance. A discussion of a closed dual economy model follows. Price difference in cases of disaster and no disaster essentially determines producers' response to the availability of a premium subsidy. A producer can obtain higher production revenue due to the significant increase in price induced by yield loss if the economy is closed and a subsistence constraint is taken into account. In this case, a premium subsidy could induce producers to lower their output level. The result is further generalized by two model extensions in which assumptions are relaxed to allow openness in the economy or intertemporal storage of grains with grain reserve policy. The findings of this article suggest that governments should carefully examine the actual risk-bearing pattern of crop producers before any subsidy policy is implemented.
\end{abstract}

Keywords output decision-making; premium subsidy; riskbearing pattern; yield-revenue relationship

\section{Introduction}

National governments frequently provide a direct subsidy to the crop insurance premium paid by producers so as to achieve varied economic and political goals. Early adopters of this policy instrument were the United States, Canada, and Japan (Barnett 2007). Recently, China, whose agricultural population is one of the world's largest, launched a similar program and heavy subsidies are now paid to producers (Shi et al. 2008; Wang et al. 2011).

Whether it is a good choice to provide subsidies to insurance premiums remains controversial although there have already been actual cases. Some researchers believe the subsidy policy is designed for income enhancement rather

\footnotetext{
* Corresponding author. E-mail: yetao@bnu.edu.cn
}

than for the purpose of risk management (Goodwin 2001). Regardless of the institutional design, Skees (1999) believes the practice of providing subsidies actually fails to produce either efficiency or equity. The subsidy instrument is also regarded as an incentive tool to allow producers to increase their output levels (Ahsan, Ali, and Kurian 1982; Nelson and Loehman 1987). The abundance of agricultural product generated by the subsidy will induce large price drops and promote social welfare, but only consumers are likely to reap the benefits. In this sense, rural producers would be better compensated by the government via redistribution policies carried out, for example, in the form of an insurance premium subsidy (Hazell 1981; Siamwalla and Valdes 1986). The "incentive" hypothesis regarding a crop insurance subsidy policy as a tool to encourage agricultural production is very attractive for some governments (Goodwin 2001). For instance, it is inferred that the major purpose of China's subsidy to crop insurance premiums is to enlarge domestic grain output, particularly after the experience of a 100 million ton drop in grain output during 1999-2003 (Swiss Re 2008).

Whether the incentive hypothesis is justifiable essentially depends on producers' investment choices in the face of uncertain returns from production when insurance coverage is available. Studies of agricultural producers' behavior have enjoyed considerable success and there are models ready to use. In the most general framework of the insurance model, a decreased effective premium rate (for example, when the actual premium rate paid by policyholders is reduced by providing a premium subsidy) will encourage policyholders to take more risk. If the same law applies to crop insurance, then producers will be encouraged to plan for higher output when a premium subsidy is provided. Previous empirical studies reveal some modest effect of a decreased premium on acreage increase in the United States (Goodwin, Vandeveer, and Deal 2004; Wu and Adams 2001). Whether this is true in a more generalized context is the main topic of this article.

The key focus of this article is producers' production behavior in response to insurance and premium rate changes. The article is organized as follows. In section 2, a classic insurance model and a crop insurance model are formulated for comparison, particularly in terms of the policyholder's 
production behavior (including output and insurance decisions) when the effective premium rate changes. Then attention shifts to the circumstances in which different statecontingent price and revenue structures occur and change producers' behavior. In section 3, we consider a stylized close economy with inelastically demanded agricultural products, just as Hazell (1981) assumed in his study. Section 4 generalizes the model in section 3 by providing two model extensions, with model specifications that are much closer to reality. Finally, the entire study is summarized and the gap between this theoretical work and possible policy implications are discussed.

\section{From the Classic Insurance Model to the Crop Insurance Model}

This section starts from the most fundamental insurance model discussing policyholders' behavior under premium subsidy. By updating the classic model, we will show the essential changes when the policyholders are agricultural producers and the price of agricultural product is taken into account.

\subsection{A Classic Model of Policyholders' Risk-Taking Behavior under Premium Subsidy}

A general description of a risk bearer's behavior under insurance can be put into a two-state model. Suppose there is an agent who is uncertain about his income return in the coming period. There are two possible outcomes, a lucky state and an unlucky state, each with probability of $\pi(0)$ and $\pi(1)$, respectively. $\pi(0)+\pi(1)=1$. In the lucky state, the agent gets a return of $X$ as planned. In the unlucky state, a proportion of $0<\delta \leq 1$ will be taken away by some adverse events and consequently the producer gets a revenue of $(1-\delta) X$. The cost for the producer to get the return of $X$ is $C(X)$, which is convex, continuous, and twice differentiable, with $C^{\prime}(\cdot)$, $C^{\prime \prime}(\cdot)>0$. Insurance for the investment is available at the cost of $v$ per unit coverage. The investor's problem is to choose the desired revenue level $X$ and insurance coverage so as to maximize the von Neumann-Morgenstern (VNM) expected utility function

$$
\max _{X, m} \mathrm{U}=\sum_{t} \pi(t) u(e(t)),
$$

in which $u(e(t))$ is the maximal welfare that the investor can obtain by choosing the best consumption bundle with statecontingent income $e(t)$. In this sense, the policyholder's utility/welfare level in a specific state only depends on income. The corresponding budget constraint is

$$
e(t)=-C(X)+(1-t \cdot \delta) X+(t-v) m, \text { for } t=0,1 . \quad \text { Eq. } 1
$$

So at the beginning of each period, the agent will have to borrow some "money" $C(X)$ to invest and insure the investment at the cost of $v m$, which is supposed to be repaid after the revenue is realized. If disasters happen in the following season, then $t=1$ and the insurance indemnity is $m$. If an interior solution is assumed, the first-order conditions for maximization satisfy

$$
-\frac{C^{\prime}(X)-(1-\delta)}{C^{\prime}(X)-1}=\frac{\pi(0) u^{\prime}(e(0))}{\pi(1) u^{\prime}(e(1))}=\frac{1-v}{v} . \quad \text { Eq. } 2
$$

Re-arrange Eq. 2 and derive comparative statics:

$$
\frac{\mathrm{d} X}{\mathrm{~d} v}=-\frac{\delta}{C^{\prime \prime}(X)}<0
$$

In Eq. $3,0<\delta \leq 1$ and $C^{\prime \prime}(\cdot)>0$ according to our assumption, it holds that a decrease in the effective premium rate will encourage the producer to produce more. In the context of this article, a decrease in the effective premium rate, $v$, can be achieved by providing a subsidy to the nominal premium rate in the market. Consequently, Eq. 3 implies that the premium subsidy will encourage producers to enlarge the output level.

\subsection{A Basic Model about Crop Producers' Behavior under Premium Subsidy}

Now we put the classic insurance model into the context of risk transfer for crop producers, by taking state-contingent prices, $p(0)$ and $p(1)$ into account. Budget constraints for the optimization problem for the producer change to

$$
\begin{gathered}
e(t)=-C(X)+p(t)(1-t \cdot \delta) X+(t-v) m, \quad \text { Eq. } 4 \\
\text { for } t=0,1 .
\end{gathered}
$$

In practice, crop insurance coverage is measured and indemnity is calculated with weights, for example kilograms or bushels. The actual economic compensation that a producer can obtain depends on actual harvest loss and price guarantee in the case of yield insurance (Barnett 2007):

$$
m=\rho \cdot \sigma \cdot \delta \cdot X \text { and } 0 \leq \rho \leq \bar{\rho} .
$$

In the equation, $\sigma$ is the predefined price guarantee, and $\rho$ is the comprehensive coverage ratio, the decision variable for the producer, which determines the percentage of the planned output $X$ that is insured. It is a compound variable consisting two variables: guarantee level and the insured proportion. The guarantee level is the critical ratio of actual yield to hypothetical yield that triggers indemnity. For instance, in the Federal Crop Insurance Program (FCIP) of the United States, a farmer can choose a guarantee level of 65,75 , or 85 percent. If the actual yield goes below 65,75 , or 85 percent of the hypothetical yield, the farmer will get paid correspondingly. The insured proportion refers to the ratio of insured acreage to total acreage that the producer operates. This ratio should not be larger than 1 , because only cultivated farmland can actually be insured. Both variables together determine the maximal proportion of the total output that is covered by insurance. This level is determined by the producer when crop insurance is purchased, but it cannot go beyond its upper limit $\bar{\rho}$, that is, 85 percent for the guarantee level and 1 for the insured proportion. 
As the coverage ratio $\rho \in[0, \bar{\rho}]$, there are three types of optimal choices: zero coverage $\rho=0$, partial coverage $0<\rho<\bar{\rho}$, and capped coverage $\rho=\bar{\rho}$, with three corresponding first-order conditions:

$$
\begin{aligned}
& X_{0}= \arg \left\{X ; \sum_{t} \lambda(t)\left[p(t)(1-t \delta)-C^{\prime}(X)\right]=0\right\} \\
& X_{\mathrm{pc}}=\arg \left\{X ;(1-v) p(0)+v p(1)(1-\delta)-C^{\prime}(X)=0\right\} \quad \text { Eq. } \\
& X_{\mathrm{fc}}=\arg \left\{X ; \sum_{t} \lambda(t)\left[p(t)(1-t \delta)-C^{\prime}(X)+(t-v) \sigma \delta\right]=0\right\} \\
& \quad \text { for } t=0,1,
\end{aligned}
$$

where the Lagrangian multiplier $\lambda(t)$ is the marginal expected ex ante utility, $\pi(t) u^{\prime}(e(t))$ with respect to income in state $t$ specified in Eq. 4. The multiplier represents the marginal utility increase/decrease in response to the change in income of each state. The first-order conditions indicate that the optimal output choice is to exactly equalize the expected marginal welfare gain/loss in both states, so that no more welfare can be obtained on average.

We are particularly interested in the producer's investment behavior change in response to the effective premium rate when interior solutions are derived, $0<\rho^{*}<\bar{\rho}$. In this sense,

$$
\frac{\mathrm{d} X}{\mathrm{~d} v}=\frac{1}{C^{\prime \prime}(X)}[p(1)(1-\delta)-p(0)],
$$

and consequently

$$
\operatorname{sign}\left[\frac{\mathrm{d} X}{\mathrm{~d} v}\right]=\operatorname{sign}[\Delta R]=\operatorname{sign}\left[\Delta p_{\mathrm{e}}\right],
$$

Eq. 7

in which $\Delta R$ is defined as the cross-state product revenue difference, $\Delta R=[p(1)(1-\delta)-p(0)] X$, and $\Delta p_{\mathrm{e}}$ is the effective price difference, $\Delta p_{\mathrm{e}}=p(1)(1-\delta)-p(0)$. The way that the producer responds to a premium change essentially depends on the cross-state revenue difference. If the producer can get higher product revenue in the unlucky state, it holds that $\Delta p_{\mathrm{e}}>0$ and consequently $\mathrm{d} X / \mathrm{d} v>0$. The producer will correspondingly reduce the output level.

\subsection{From the Classic Insurance Model to the Crop Insurance Model}

The classic insurance model could be regarded as a special case among crop insurance models by assuming equal prices across states. But there are substantial differences in the economic implications between the two models:

(1) The loss in yield (substantial) and the loss in revenue (monetary)

The key difference between the loss in yield and the loss in revenue is the price system, particularly when statecontingent prices are different. Producers are surely victims in terms of yield loss but not necessarily losers of product revenue. For certain types of agricultural product, especially fresh fruits and vegetables, a temporary shortage in supply could raise the price much more significantly than the size of drop in supply, and some suppliers may benefit instead. In this sense, the yield-revenue relationship rather than the yieldprice relationship is critical when producers' behavior under conditions of uncertainty is discussed. Negative correlation between yield and price is generally assumed (Wang, Hanson, and Black 2003; Innes 2003; Babcock and Hennessy 1996) instead of a negative yield-revenue correlation.

(2) The loss in yield (substantial) and the insurance indemnity (monetary)

The second issue is whether the loss in yield can be compensated by providing monetary insurance indemnity, particularly when yield loss and indemnity have different roles to play in maintaining utility. When the goods for providing utility are assumed to be perfectly substitutable the answer is yes. Otherwise, the answer depends on whether there is a large free market from which policyholders can purchase enough agricultural products with monetary indemnities paid by insurers. In reality this situation is usually not the case. The price in the domestic market is likely to rise after a disaster event. The international food market is a high friction institution and the price is usually highly loaded because of transaction costs. Even if producers are compensated monetarily, aggregate products remain in short supply, and the price could go beyond the affordable means of consumers. Foreign insurance contracts could even induce inflation in some local areas, because of an oversupply of money.

\section{Crop Insurance Model in a Closed Economy with Subsistence Constraint}

The comparison in the last section reveals the critical difference between a generalized model describing policyholder's risk-taking behavior in response to insurance price change, and its specification to a crop insurance case. Can there exist the case of an unusual state-contingent revenue structure in which a producer earns more when a disaster occurs? The answer requires further specification of the economy. In this section, by providing the details of an entire economy, a closed dual economy is considered for the discussion, which can be regarded as a further specification of the crop insurance model discussed in section 2.2.

\subsection{Model Assumptions}

Consider a closed economy with two sectors, agricultural (A) and manufactory $(\mathrm{M})$, producing homogeneous agricultural products (A-goods) and homogeneous manufacturing products (M-goods), respectively. M-goods are assumed to be able to transact internationally and serve as the numéraire in the model. There is a population of laborers with a proportion of $n$ working in the agriculture sector who are called "producers" and $(1-n)$ working in the manufactory sector, called "workers." Without loss of generality, the population is 
normalized to 1 . The allocation parameter $n$ is exogenously determined, reflecting a long-term equilibrium where the share of population engaging in farming and manufactory remains unchanged.

The model is in a static framework, with economic activities repeating period by period. Individuals are usually assumed in the literature to be rational utility maximizeers. At the end of each period, the consumption stage, each individual tries to maximize the ex post utility level provided by known labor income and prices of goods, $V(p(t), e(t))=$ $\arg \max u(x(t), y(t))$ s.t. $p(t) x(t)+y(t)=e(t)$, for $t=0,1, x(t)$ and $y(t)$ denote state-contingent consumption of A-goods and $\mathrm{M}$-goods, correspondingly. State-contingent social aggregate A-goods available for consumption are the plain aggregation of individual output, $\sum X(t)=n(1-t \delta) X$. It is assumed that the M-sector is bared little risk, and under necessary assumptions social aggregate M-goods for consumption will be simply total wages paid to workers, $(1-n) w$, minus the part used in agricultural production, $Y=(1-n) w-n C(X)$. In this sense, the social budget constraint follows

$$
\begin{aligned}
& n x_{1}^{*}(t)+(1-n) x_{2}^{*}(t) \leq \sum X(t) \\
& n y_{1}^{*}(t)+(1-n) y_{2}^{*}(t) \leq Y
\end{aligned} \text {, for } t=0,1, \quad \text { Eq. } 8
$$

where variables with “"*” denote optimal choice, and subscripts " 1 " and " 2 " represent farmers and workers, correspondingly. In other words, the aggregate amount of A-goods and Mgoods consumed by farmers and workers should not exceed the actual product available. Given the information provided above, equilibrium can be derived according to Walras' Law, by assuming interior solutions, determined by the vector of state-contingent prices, $p(t)$.

At the beginning of each period, each producer makes a production decision to maximize his expected ex ante utility. Constant relative risk aversion (CRRA) preference is assumed, $W(V)=V^{1-\theta} /(1-\theta)$ for $\theta>0, \theta \neq 1$ and $\ln (v)$ for $\theta=1$, as suggested by Myers (1989). Producers have the similar planning problem to section 2.2:

$$
\max _{X, \rho} \mathrm{E} W_{1}=\sum_{t} \pi(t) W\left(V_{1}\left(e_{1}(t), p(t)\right)\right)
$$

subject to:

$$
\begin{aligned}
\lambda_{1}(t): e_{1}(t) & =p(t)(1-t \delta) X-C(X) \\
& +(t-v) \cdot \sigma \cdot \Delta \cdot X \cdot \rho, \quad \text { for } t=0,1, \quad \text { Eq. } 9 \\
\lambda_{2}: 0 \leq \rho \leq & \bar{\rho}
\end{aligned}
$$

in which $V_{1}(\cdot)$ is the ex post maximized indirect utility function. The Greek letter ahead of each budget constraint is its corresponding Lagrangian multiplier. The first-order condition will be identical to Eq. 6 in the analytical form, except $\lambda_{1}(t)=\pi(t) \partial W\left(V_{1}\left(e_{1}(t), p(t)\right)\right) / \partial e_{1}(t)$ in which the ex ante utility function $W_{1}(\cdot)$ is incorporated.

\subsection{Ex Post Equilibrium under Subsistence Constraint}

The model stresses the impact of the subsistence constraint on state-contingent prices of A-goods. Constant elasticity of substitution (CES) utility functions with negative elasticity would be good choices. An alternative is to set a constant $\bar{x}$ in the C-D utility function, denoting the minimal level of $x$ to maintain utility, known as the Stone-Geary utility function (Neary 1997), for example, $u(x, y)=A \cdot(x-\bar{x})^{\alpha} y^{1-\alpha}$, with $0<\alpha<1$ and $A=\alpha^{-\alpha}(1-\alpha)^{\alpha-1}$ used to simplify denotation. The Stone-Geary utility families are widely adopted in macro economic growth models. With this assumption, individuals' ex post indirect utility level $V_{i}\left(e_{i}(t), p(t)\right)$ is a linear system with respect to labor income used for non-subsistence consumption (in the Stone-Geary system, $p(t) \bar{x}$ is part of the expenditure used for "subsistence consumption"):

$$
\begin{gathered}
V(e(t), p(t))=\arg \max _{x, y} u(x, y)=p(t)^{-\alpha}[e(t)-p(t) \bar{x}], \\
\text { for } t=0,1,
\end{gathered}
$$

in which $p(t)$ is the relative price of the A-goods relative to the M-goods. The rural producer's labor income follows $e_{1}(t)=$ $p(t) \delta(t) X-C(X)$, which reflects product revenue minus the costs for production, and the urban worker's labor income is $e_{2}(t)=e_{2}=w$, the wage paid by firms, for $t=0,1$.

Given the specifications above, the ex post equilibrium can be derived by specifying the Stone-Geary utility function, solving for the individual optimal consumption bundle $\left(x_{i}^{*}(t), y_{i}^{*}(t)\right)$ and inserting both into Eq. 8:

$$
p(t)=\frac{\alpha}{1-\alpha} \frac{Y}{n(1-t \delta) X-\bar{x}}, \text { for } t=0,1, \quad \text { Eq. } 11
$$

which is determined by the ratio between social aggregate M-goods available for consumption and social aggregate A-goods available for non-subsistence consumption, and the elasticity of substitution between A-goods and M-goods.

The basic features of the ex post equilibrium can be highlighted by inequalities, $e_{1}(0)<e_{1}(1)$ and $V_{2}(0)>V_{2}(1)$ : a loss in yield may not necessarily induce a loss in revenue. ${ }^{\text {ii }}$ Due to the inelastic demand of crop goods, a drop in crop supply may induce larger price increases, and consequently revenue may still increase. Note that this result is also valid for other instant utility families, such as the CES utility families with a complementary relationship between goods. When $\bar{x}$ goes down to 0 , or the elasticity of substitution between goods returns to unit if another CES utility family is assumed, the utility function collapses to the Cobb-Douglas type, the product revenue will be reserved across both states, where $p(t)(1-t \cdot \delta)=$ constant.

For further discussion, note that a long-run equilibrium in the cross-sector labor market implies $e_{1}(0)<e_{2}<e_{1}(1)$. If producers always get less labor income than workers, then gradually the urban sector will attract more laborers, or vice versa. With this structure, it holds that $\left|\Delta V_{1}\right|<\left|\Delta V_{2}\right|$ and $\operatorname{Var}\left(V_{1}\right)<\operatorname{Var}\left(V_{2}\right)$ iii $\operatorname{Recall}$ the ex post indirect utility function of Eq. 10. It has two components, the price factor $p(t)^{-\alpha}$ and the income factor $[e(t)-p(t) \bar{x}]$. Correspondingly, the impact of disaster on the ex post indirect utility can be decomposed into two pieces of effect, the "price effect" $(P E)$ and the "revenue effect" $(R E)$ : 


$$
\begin{aligned}
\Delta V_{i}= & V_{i}\left(e_{i}(1), p(1)\right)-V_{i}\left(e_{i}(0), p(0)\right) \\
= & \underbrace{V_{i}\left(e_{i}(0), p(1)\right)-V_{i}\left(e_{i}(0), p(0)\right)}_{P E_{i}} \\
& +\underbrace{V_{i}\left(e_{i}(1), p(1)\right)-V_{i}\left(e_{i}(0), p(1)\right)}_{R E_{i}}
\end{aligned}
$$

If the unlucky state is initiated by nature, the price effect is negative to all individuals, $P E_{i}<0$, for $i=1$, 2 , because the rise in price undermines purchasing power. Workers' incomes are not affected as assumed and $R E_{2}=0$. Producers can get higher revenue which creates positive effects to the statecontingent utility, $R E_{1}>0$. In this sense, the drop in producers' utility is certainly smaller than the one in the workers', since the revenue effect offsets a part of the negative effect induced by the rise in price.

The state-contingent utility structure reveals the actual risk-bearing pattern in this economy in which urban workers actually bear more risks than rural producers. This pattern is quite different from the model's assumption that disasters happen only to the rural sector and the urban sector is riskfree. This effect is a direct consequence of the subsistence constraint and a closed-static economy, which shifts most of the risks from producers to workers (pure consumers of A-goods). Under this framework, it is impossible to use a domestic insurance market to transfer risk from rural producers to urban consumers if they are homogeneously risk-averse. This could be one reason why crop insurance programs fail.

\subsection{Producers' Production Behavior and Crop Insurance}

Following the discussion in section 2.2 it is straightforward that

$$
\mathrm{d} X_{\mathrm{pc}} / \mathrm{d} v>0, X_{\mathrm{pc}}<X_{0} .
$$

The producer sector will reduce its output level when the effective premium rate drops, if it partially insures its crop production. A premium subsidy policy can stimulate producers to produce more than is the case if no insurance is available provided that the coverage is offered for free. The supply function of the producers with respect to the effective premium rate is depicted in Figure 1. In the figure, the first quadrant represents the demand function of crop insurance, crop insurance coverage $m$ as a function of premium rate $v$. Subscripts "pc" and "fc" represent the cases of partial coverage and full coverage, correspondingly. The second quadrant reveals the relationship between output decision $X$ and effective premium rate $v$. There are critical turning points on both curves, showing significant difference between the cases of partial coverage and full coverage.

There are several critical values of $v$ in figure 1 .

(1) $v_{0}$ is the critical effective premium rate that makes a rural producer indifferent of purchasing insurance coverage. $v_{0}=\lambda_{1}(1) /\left.\sum_{t} \lambda_{1}(t)\right|_{\rho=0}<1$, the weight of the expected

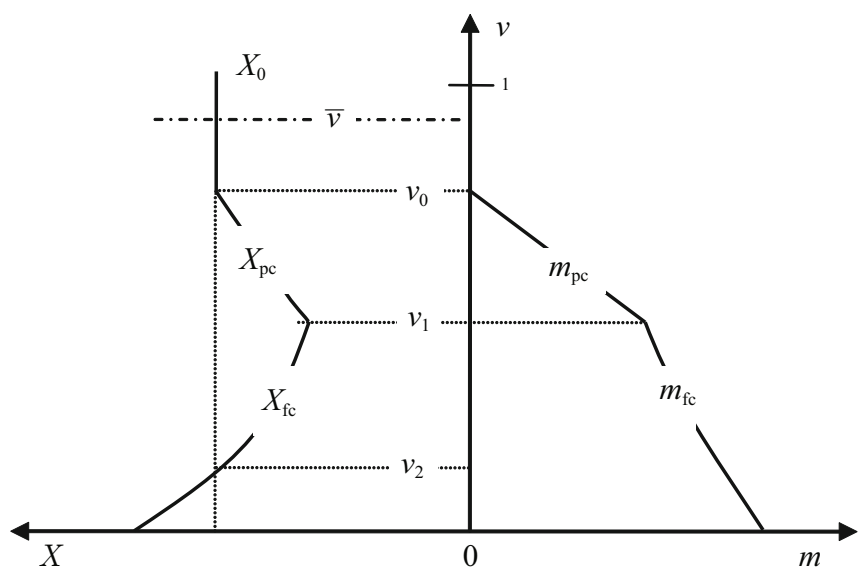

Figure 1. Production behavior and insurance demand of the rural producer

marginal ex ante utility associated to the unlucky state, $\lambda_{1}(t)=\pi(t) \partial W\left(V_{1}\left(e_{1}(t), p(t)\right)\right) / \partial e_{1}(t)$.

(2) $v_{1}$ is the critical effective premium rate that makes a rural producer indifferent to capped coverage and partial coverage. This function is located at the intersection of $X_{\mathrm{pc}}$ and $X_{\mathrm{fc}}$.

(3) $v_{2}$ is the intersection point of $X_{\mathrm{fc}}$ and $X_{0}$. Producers will produce more than the benchmark case only if the effective premium rate is cheaper than $v_{2}$.

\section{Two Extensions towards Reality}

The purpose of this section is to address the production behavior of producers in a more flexible and realistic framework. Two extensions to the model in the previous section are provided, considering: (1) the openness of the economy; and (2) techniques for cross-period storage of the A-goods, such as a grain reserve policy and storage facilities.

\subsection{The Openness of the Economy}

The first alternative setting of the model is to open the economy. Suppose that the international market is providing a stable and unlimited supply of both A-goods and M-goods, which are perfectly substitutable for domestic ones. In the simplest case, assume that the economy is perfectly open and local people are free to access the international market for both goods. In this sense, the domestic price of A-goods will converge toward the price level existing in the international market. If originally the domestic price is lower than the international price, local producers will increase their price to the international level because potentially they can sell their output to the international market. Or if the domestic price is higher than the international one, the local producer will have to drop the local price. Otherwise no consumer will buy 
A-goods from them. Perfect openness diminishes the statecontingent price difference. Consequently, the rural producer bears all the output risk. The model collapses to the most general case of a uniform price structure or the classic insurance model.

Consider the case of a semi-open economy for A-goods instead. Goods still are perfectly substitutable. There is a price for A-goods in the international market, $p_{\mathrm{f}}$. But local A-goods are not able to access the international food market, for reasons such as prohibited A-goods exportation, or hightransaction costs in exportation. Consequently, there is no chance for the domestic price to converge to the international one.

Briefly, there could be three cases in this semi-open economy. If the price in the international market is low enough, such that $p_{\mathrm{f}}<p(0)<p(1)$, then local producers have to sell their A-goods at the international price, because otherwise every consumer will choose to buy from the international market. If the international price lies exactly in between the domestic prices in the lucky state and the unlucky state, $p(0)<p_{\mathrm{f}}<p(1)$, then in the lucky state, producers sell at the domestic price $p(0)$ while in the unlucky state, local producers have to sell at the price $p_{\mathrm{f}}$. In the last case, if $p(0)<p(1)<p_{\mathrm{f}}$, then the equilibrium will be equivalent to the one mentioned in the previous section and the international food market is in effect not working.

Therefore, price in the unlucky state changes to $\bar{p}=\min \left\{p(1), p_{\mathrm{f}}\right\}$ and it holds that

$$
\frac{\mathrm{d}\left(\Delta p_{\mathrm{e}}\right)}{\mathrm{d} \bar{p}}=(1-\delta)-\frac{\mathrm{d} p(0)}{\mathrm{d} X_{\mathrm{pc}}} \frac{\mathrm{d} X_{\mathrm{pc}}}{\mathrm{d} \bar{p}}>0 .
$$

This means that the difference between state-contingent effective prices is monotonically increasing with the increase in price in the unlucky state. If $p_{\mathrm{f}} \geq p(1)$, it holds that $\Delta p_{\mathrm{e}}$, $\Delta R>0$ and is equivalent to the benchmark case. If the international price is exactly $p_{\mathrm{f}}=p(0)$, it holds that $\Delta p_{\mathrm{e}}, \Delta R<0$. If $\Delta R$ is a monotonically increasing function with respect to $\bar{p}$, there mustbe a critical international price $p(0)<p_{\mathrm{f}}^{*}<p(1)$ that allows $\Delta p_{\mathrm{e}}, \Delta R=0$, and

(1) If $p(0) \leq p_{\mathrm{f}}<p_{\mathrm{f}}^{*}$ and $\Delta p_{\mathrm{e}}, \Delta R<0, \mathrm{~d} X_{\mathrm{pc}} / \mathrm{d} v<0$. The drop in the effective premium rate encourages producers to enlarge their outputs. This case converges to the most general case in section 2.1 where state-contingent prices are not taken into account, just as described in Eq. 3 .

(2) If $p_{\mathrm{f}}=p_{\mathrm{f}}^{*}$ and $\Delta p_{\mathrm{e}}, \Delta R=0, \mathrm{~d} X_{\mathrm{pc}} / \mathrm{d} v=0$. The drop in the effective premium rate has no impact on the desired output level.

(3) If $p_{\mathrm{f}}^{*}<p_{\mathrm{f}}$ and $\Delta p_{\mathrm{e}}, \Delta R>0, \mathrm{~d} X_{\mathrm{pc}} / \mathrm{d} v>0$. The drop in the effective premium rate induces producers to reduce their output. This case converges to the case described in section 3.3 and Figure 1.

\subsection{Grain Reserve Policy}

Another case that may generalize the basic model to more realistic cases is the grain reserve policy, which is an application of the classic buffer-stock strategy for grain products. It is a well known instrument for intertemporal spreading of grain supply risk. The risk is that natural disasters may happen and destroy some proportion of a harvest. With a grain reserve, generally the government puts grains into the market to increase supply and prevent the price from going too high when supply drops due to natural events. Those grains could be either stored before the disaster occurs when there was a good harvest, or bought from the international food market when food shortfalls are obvious.

What is going to happen if the government of the closedeconomy in the basic model decides to adopt a grain reserve policy? For each state $t$, the government may reduce or increase the market supply by $g(t)$. In this sense,

$n x_{1}^{*}(t)+(1-n) x_{2}^{*}(t)=n(1-t \delta) X+g(t)$, for $t=0,1$. Eq. 14

There are several ways for the government to do so (Ye 2009). For instance, it can be done merely in substantial form, collecting and storing grains in lucky states and later put these grains to the market in unlucky states. Alternatively, the government may follow market transaction and fluctuations through buying and selling. If the government adopts an intervention approach, which is neutral to the ex post price system, state-contingent prices change to

$$
\hat{p}(t)=\frac{\alpha}{1-\alpha} \frac{Y}{n(1-t \delta) X-\bar{x}+g(t)}, \text { for } t=0,1, \quad \text { Eq. } 15
$$

where the circumflex symbol is used as a reminder that the price in Eq. 15 is different from earlier cases. The word "neutral" refers to the fact that the ex post equilibrium price is still determined by the ratio of total A-goods and M-goods available in the market. So it follows that $\mathrm{d} p(t) / \mathrm{d} g(t)<$ $0<\mathrm{d}^{2} p(t) / \mathrm{d} g(t)^{2}$, for $t=0$, 1 . State-contingent prices are convex sets of their corresponding intervention variable.

The state-contingent intervention actions, $g$, must follow the budget constraint for the government, that is, the grain stored in the lucky years must be able to support grain used in the unlucky years, $\sum_{t} \pi(t) g(t) \geq 0$, on average. The simplest case is to assume that the storage technique is perfect and there is no time-discount factor for both the quality and quantity of grains reserved, $\sum_{t} \pi(t) g(t)=0$.

Similar to the discussion in section 4.1, we are interested in the impact of a grain reserve policy on the cross-state effective revenue/price difference, which essentially determines producers' behavior.

$$
\begin{aligned}
\frac{\mathrm{d}\left(\Delta p_{\mathrm{e}}\right)}{\mathrm{d} g(0)}= & \frac{\mathrm{d} \hat{p}(1)}{\mathrm{d} g(1)} \frac{\mathrm{d} g(1)}{\mathrm{d} g(0)}(1-\delta)-\frac{\mathrm{d} \hat{p}(0)}{\mathrm{d} g(0)}>0, \\
& \text { for } i=0, \mathrm{pc}, \text { fc. }
\end{aligned}
$$

Eq. 16 says that if the government reduces the market supply of A-goods in the lucky state $(g(0)<0)$ and increases that supply in the unlucky state, the state-contingent effective price difference will shrink. In this sense, there must be two critical intervention vectors: $(1) \boldsymbol{g}^{*}$, which allows $\hat{p}(0)=\hat{p}(1)$ and $\Delta R<0$, and (2) $g^{* *}$, which holds $\hat{p}(0)=\hat{p}(1)(1-\delta)$, and $\Delta R=0$ 
Therefore, the following observations are obtained:

(1) If $\boldsymbol{g}^{* *}<\boldsymbol{g}<\boldsymbol{g}^{*}$ and $\Delta R<0, \mathrm{~d} X_{\mathrm{pc}} / \mathrm{d} v<0$. The drop in the effective premium rate encourages producers to enlarge their outputs, as described in Eq. 16.

(2) If $\boldsymbol{g}=\boldsymbol{g}^{* *}$ and $\Delta R=0, \mathrm{~d} X_{\mathrm{pc}} / \mathrm{d} v=0$. The drop in the effective premium rate has no impact on the desired output level.

(3) If $0<\boldsymbol{g}<\boldsymbol{g}^{* *}$ and $\Delta R>0, \mathrm{~d} X_{\mathrm{pc}} / \mathrm{d} v>0$. The drop in the effective premium rate induces producers to reduce their outputs. This case converges to the case described in section 3.3 and Figure 1.

\subsection{Summary of the Model and Extensions}

Model extensions described in section 4.1 and 4.2 are generalized as in Figure 2.

In Figure 2 there are four parallel $\mathrm{x}$-axes. The top one represents major factors, which could either be the international food market price $p_{\mathrm{f}}$ or government intervention strength $\mathbf{g}$. The axis immediately below represents the cross-state price difference. The third axis denotes the cross-state product revenue / effective price difference. The bottom axis shows the allocation of risk between two groups of people: urban consumers and rural producers. Each point on the four axes corresponds to the same point on each of the other axes. The left y-axis refers to the benchmark case, where we have neither an international food market (or $p_{\mathrm{f}} \geq p(1)$ ) nor government intervention $(g=0)$, both price difference and revenue difference are negative, and urban consumers are bearing all the risks related to a reduction in the production of A-goods.

Critical case 1 refers to either $p_{\mathrm{f}}=p_{\mathrm{f}}^{*}$ or $\boldsymbol{g}=\boldsymbol{g}^{* *}$, which exactly allow $\Delta p_{\mathrm{e}}<0$, as well as $\Delta p<0$. At this point, the urban consumer and the rural producer bear the same amount of risk in the price system, since people in both groups have certain incomes but face the same uncertain price. Particularly if the long-run equilibrium in the labor market is taken into account, and if at equilibrium the urban consumer and the rural producer have the same ex ante expected utility level, case 1 will be the risk-equivalent point for the rural producer and the urban consumer. Critical case 2 refers to $p_{\mathrm{f}}=p(0)$ or $\boldsymbol{g}=\boldsymbol{g}^{*}$, which exactly allow $\Delta p=0$ and $\Delta p_{\mathrm{e}}<0$. At this point, urban consumers will be risk-free since the income as well as

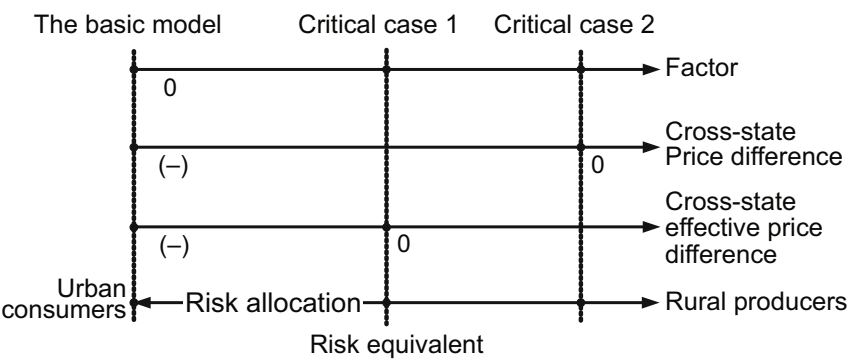

Figure 2. Cross-state price and revenue difference and risk allocation under different model assumptions market price is certain. Rural producers are bearing all the risk in this economy.

It is worth noting that from the benchmark case to the critical cases, the change is not necessarily discrete. There is a continuum of cross-state price differences, effective price / product revenue differences, and risk-allocation patterns between the urban consumer and the rural producer, for any arbitrary values on the factor axis. In this sense, we partially bridge the ideal model benchmark to reality to some degree. In the region between the benchmark and the critical case 1, a drop in the premium rate of crop insurance will induce producers to reduce their optimal output level. This situation is rarely observed in reality because of the existence of an international food market and government intervention. What we have observed generally is that the market price fluctuates around $p(0)$, and of course the implications change correspondingly.

\section{Conclusion}

In this article, we have distinguished the difference between classic insurance theory and its application to crop insurance programs. The article also investigates the general hypothesis that a reduced price for risk-transfer encourages risk bearers to take on more risk in their investment. The discussion about agricultural producers' production behavior under a premium subsidy policy is put in the context of a basic model with closed dual economy and its two extensions, the openness of the economy and a grain reserve policy. The stylized model reveals the original structure of producers' behavior under crop insurance, where the cross-state revenue structure is essential. Although the benchmark model derives logical but unrealistic results, its extensions successfully fill the gap. The two extensions are more generalized forms than the benchmark model and incorporate more flexible cross-state price structures.

Several observations are important from this model. First, critical parameters in crop insurance models, including loss in yield, loss in revenue, and insurance indemnity, are essentially different in terms of their function in maintaining producers' utility. It is critical to take the price system into account so as to observe such differences.

Second, it is the actual risk-bearing pattern that determines the supplier and the demander of domestic crop insurance. This actual risk-bearing pattern may not necessarily coincide with the one assumed. For instance, in the benchmark model, rural producers are the direct risk-bearers but eventually it is the urban consumers who are affected by the yield loss risk. When the model is generalized and more flexible cross-state price structures are assumed, the pattern of risk-bearing changes correspondingly.

Last but not least, whether a producer will increase output level depends on several issues. If the capping issue is not taken into account, then output levels are essentially determined by the state-contingent revenue structure. The model gives examples of how the state-contingent revenue 
structure may differ. Price of the agricultural product and its foreign substitutes, and the feasibility of intertemporal storage, may have considerable impact on the revenue structure, and consequently producers will respond differently should the effective premium rate drop.

Policy implications of the modeling for governmentsubsidized crop insurance programs is also an important outcome, although in many countries existing practice is correct according to the model's results. In most realistic cases, rural producers suffer from product revenue decline induced by disasters and they are the true bearer of risks. Reducing the effective premium rate by providing a subsidy encourages rural producers to enlarge their output level. A premium subsidy can also be justified as it provides financial aid to producers, who are victims of the risks incurred, particularly when a grain reserve policy is adopted. For certain crop regions where the price structure allows higher revenue when there is a fall in crop yield than the case when there is a normal harvest, as has been illustrated by our models, the subsidy approach is not suggested since it only leads to the opposite effect of reduced output.

\section{Acknowledgments}

This study was supported financially by the National Natural Science Foundation of China under grant 41001357 and the Scientific Research Foundation of Beijing Normal University.

\section{Notes}

i Interior solution means that the optimal choice lies in the constraint set rather than on the boundary of the constraint set. If the optimal choice lies exactly on the boundary of the constraint set, it is called binding solution. For instance, if we have an inequality constraint $h(x) \leq y$, optimal solutions that allow $h\left(x^{*}\right)<y$ are interior solutions, while solutions that allow $h\left(x^{*}\right)=y$ are binding solutions.

ii The revenue difference in both states can be denoted as: $p(0) X-p(1)(1-\delta) X=\frac{\alpha}{1-\alpha} Y X \frac{\delta \bar{x}}{[n X-\bar{x}][n(1-\delta) X-\bar{x}]}$. For any

$1>\delta \geq 0$, it necessarily holds that $p(0) X-p(1) \delta X<0$.

iii From Eq. 10 it can be derived that

$$
\begin{aligned}
\Delta V_{1}-\Delta V_{2} & =\left[V_{1}(1)-V_{1}(0)\right]-\left[V_{2}(1)-V_{2}(0)\right] \\
& =-p(0)^{-\alpha}\left[e_{1}(0)-e_{2}(0)\right]+p(1)^{-\alpha}\left[e_{1}(1)-e_{2}(1)\right]
\end{aligned}
$$

When it is assumed $e_{1}(0)<e_{2}(0)=e_{2}(1)<e_{1}(1)$, it holds that $0>\Delta V_{1}>\Delta V_{2}$.

$$
\operatorname{Var}\left(v_{i}\right)=\mathrm{E}\left\{\left[V_{i}(t)-\mathrm{E} V_{\mathrm{i}}\right]^{2}\right\}=\pi(0) \pi(1)\left(\Delta V_{i}\right)^{2} .
$$

Consequently $\operatorname{Var}\left(v_{1}\right)<\operatorname{Var}\left(v_{2}\right)$.

\section{References}

Ahsan, S. M., A. A. G. Ali, and N. J. Kurian. 1982. Toward a Theory of Agricultural Insurance. American Journal of Agricultural Economics 64 (3): 520-29.

Babcock, B. A., and D. Hennessy. 1996. Input Demand under Yield and Revenue Insurance. American Journal of Agricultural Economics 78 (2): 416-27.

Barnett, B. J. 2007. The U.S. Federal Crop Insurance Program. Canadian Journal of Agricultural Economics 48 (4): 539-51.

Goodwin, B. K. 2001. Problems with Market Insurance in Agriculture. American Journal of Agricultural Economics 83 (3): 643-49.

Goodwin, B. K., M. L. Vandeveer, and J. L. Deal. 2004. An Empirical Analysis of Acreage Effects of Participation in the Federal Crop Insurance Program. American Journal of Agricultural Economics 86 (4): 1058-77.

Hazell, P. 1981. Crop Insurance-A Time for Reappraisal. IFPRI Report $3,1-4$.

Innes, R. 2003. Crop Insurance in a Political Economy: An Alternative Perspective on Agricultural Policy. American Journal of Agricultural Economics 85 (2): 318-35.

Myers, R. J. 1989. Econometric Testing for Risk Averse Behavior in Agriculture. Applied Economics 21 (4): 541-52.

Neary, J. P. 1997. R. C. Geary's Contributions to Economic Theory. Working papers from College Dublin, Department of Political Economy. http://www.economics.ox.ac.uk/members/peter.neary/papers/ pdf/geary97.pdf.

Nelson, C. H., and E. T. Loehman. 1987. Further Toward a Theory of Agriculture Insurance. American Journal of Agricultural Economics 69 (3): 523-31.

Shi, P. J., D. Tang, J. Liu, B. Chen, and M. Q. Zhou. 2008. Natural Disaster Insurance--Issues and Strategy of China. In Asian Catastrophe Insurance, edited by C. Scawthorn and K. Kobayashi, 79-93. London: Risk Books.

Siamwalla, A., and A. Valdes. 1986. Should Crop Insurance Be Subsidized? In Crop Insurance for Agriculture Development: Issues and Experiences, edited by P. Hazell, C. Pomareda, and A. Valdes, 117-25. Baltimore: Johns Hopkins University Press.

Skees, J. 1999. Agricultural Risk Management or Income Enhancement? Regulation 22 (1): 35-43.

Swiss Re (Swiss Reinsurance Company Ltd.) 2008. Setting up Sustainable Agricultural Insurance: The Example of China. http://www. swissre.com/pws/research\%20publications/risk\%20and\%20expertise/ focus\%20reports/agro_china.html.

Wang, H. H., S. D. Hanson, and J. R. Black. 2003. Efficiency Costs of Subsidy Rules for Crop Insurance. Journal of Agricultural and Resources Economics 28 (1): 116-37.

Wang, M., P. J. Shi, T. Ye, M. Liu, and M. Q. Zhou. 2011. Agriculture Insurance in China: History, Experience, and Lessons Learned. International Journal of Disaster Risk Science 2 (2): 10-22.

Wu, J., and R. M. Adams. 2001. Production Risk, Acreage Decisions and Implications for Revenue Insurance Program. Canadian Journal of Agricultural Economics 49 (1): 19-35.

Ye, T. 2009. Inter-Sectoral and Inter-Temporal Diversification of Agricultural Disaster Risk: Equilibrium Analysis of Risk Sharing Puzzle and the Role of Government. Ph.D. dissertation, Kyoto University.

Open Access This article is distributed under the terms of the Creative Commons Attribution License which permits any use, distribution, and reproduction in any medium, provided the original author(s) and source are credited. 